\title{
Nutritional composition and bioactivity of Umbilicus rupestris (Salisb.) Dandy: An underexploited edible wild plant
}

\author{
Júlia Harumi Iyda ${ }^{\mathrm{a}, \mathrm{b}}$, Ângela Fernandes ${ }^{\mathrm{a}}$, Ricardo C. Calhelha ${ }^{\mathrm{a}}$, Maria José Alves $^{\mathrm{a}}$, \\ Flávio Dias Ferreira ${ }^{\mathrm{b}}$, Lillian Barros ${ }^{\mathrm{a}}$, Joana S. Amaral ${ }^{\mathrm{a}, \mathrm{c}, *}$, Isabel C.F.R. Ferreira ${ }^{\mathrm{a}, *}$ \\ ${ }^{a}$ Centro de Investigação de Montanha (CIMO), Instituto Politécnico de Bragança, Campus de Santa Apolónia, 5300-253 Bragança, Portugal \\ ${ }^{\mathrm{b}}$ Departamento Acadêmico de Alimentos (DAALM), Universidade Tecnológica Federal do Paraná, Campus Medianeira, 85884-000 Paraná, Brazil \\ ${ }^{\mathrm{c}}$ REQUIMTE/LAQV, Faculdade de Farmácia da Universidade do Porto, 4050-313 Porto, Portugal
}

\section{A R T I C L E I N F O}

\section{Keywords:}

Umbilicus rupestris

Nutritional value

Chemical characterization

Phenolic compounds

Bioactive properties

\begin{abstract}
A B S T R A C T
The inclusion of edible wild plants in human diet has been receiving an increasing attention, as they represent an easily accessible source of nutrients, vitamins and antioxidants. In this work, the leaves of Umbelicus rupestris (Salisb.) Dandy, an edible species for which only scarce data is available in literature, were thoroughly evaluated for its nutritional profile, chemical characterization and bioactive properties. Being considered a succulent plant, the leaves revealed a very high content of moisture, with several beneficial compounds, including omega-3 polyunsaturated fatty acids, tocopherols and different polyphenols. A total of twelve flavonoids, three phenolic acids and one phenylpropanoid glucoside were identified in the decoction and/or hydroethanolic extracts, with most of them being described for the first time in this plant. Both extracts showed antioxidant activity and potential to inhibit some of the assayed bacteria, while not presenting cytotoxic effects on a non-tumour primary cell culture.
\end{abstract}

\section{Introduction}

Wild vegetables represent an important resource for humans worldwide, not only for their nutritional potential, as they are an inexpensive source of nutrients, vitamins, antioxidants and minerals, but also as a cultural heritage that should be protected (Ferreira, Morales, \& Barros, 2016; Pardo-de-Santayana et al., 2007). In several areas of the globe, such as the Mediterranean region, different vegetables that grow spontaneously without being cultivated are still traditionally consumed and play an important role in the diet of local populations, in particular of those living in more rural areas. Nevertheless, this knowledge acquired during centuries and transmitted among generations, is facing an increasing risk of being lost due to a growing pressure of globalization, with some wild edible plants that were once used, now being rarely or no longer consumed (Geraci, Amato, Di Noto, Bazan, \& Schicchi, 2018; Łuczaj et al., 2012; Pardo-de-Santayana et al., 2007). Fortunately, in the last years, wild edible plants have been receiving more attention not only from the scientific community, with the performance of ethnobotanical studies that allows documenting this ancient knowledge and studies comprising their chemical characterization, but also from the food industry and consumers, which are increasingly interested in sustainable and healthy foods. Additionally, across Europe and several developed countries, a new trend has been recently emerging in nutrition and contemporary cuisine, leading to an increasing incorporation of local wild plants in modern dishes as an element of cultural identity but also seeking their health benefits (Geraci et al., 2018; Łuczaj et al., 2012).

Umbilicus rupestris (Salisb.) Dandy, commonly called navelwort or wall pennywort, is an edible wild plant that belongs to the Crassulaceae family, being characterized by a deformity in the leaf centre forming a navel (Gonzáles, Román, \& Castro, 2009). U. rupestris is a succulent plant native from the Western Europe and the Mediterranean region, being frequently found in stone walls, cliffs and rock faces, preferring shaded and moist places (Afferni, 2009; Daniel, Woodward, Bryant, \& Etherington, 1985). Due to the limited availability of soil in these habitats, the plant is often exposed to intermittent drought periods. When exposed to water stress, $U$. rupestris presents the capacity of switching from C3 photosynthesis to Crassulacean Acid Metabolism (CAM), a key adaptation typically found in a wide range of succulent plants, characterized by the closing of stomata during the day and opening at night when evaporative water loss is lower (Daniel et al., 1985).

Being a succulent plant, $U$. rupestris is mainly consumed raw in

\footnotetext{
*Corresponding authors at: Centro de Investigação de Montanha (CIMO), Instituto Politécnico de Bragança, Campus de Santa Apolónia, 5300-253 Bragança, Portugal (J.S. Amaral).

E-mail addresses: jamaral@ipb.pt (J.S. Amaral), iferreira@ipb.pt (I.C.F.R. Ferreira).
} 
salads since its leaves have a fleshy crunchy texture (Geraci et al., 2018; Pardo-de-Santayana, Morales, Tardío, \& Molina, 2018; Torija-Isasa \& Matallana-González, 2016). Generally, the younger leaves are preferred for their mild flavour, especially in winter and early spring, because as the plant matures the leaves become bitter and not so pleasant-tasting. As happens with many plants from the Mediterranean flora, besides being used as food, ethnobotanical surveys have reported the usefulness of $U$. rupestries leaves in traditional medicine, namely against the inflammation and irritation of the skin, to treat furuncles, as disinfectant of wounds and with healing properties of burns (Benhouda \& Yahia, 2015; Vickery, 2019). According to Allen and Hatfield (2004), in Britain and Ireland folk tradition, $U$. rupestries has been valued for soothing and healing soreness of the skin, calluses and as a treatment for various kinds of skin eruptions. The leaves can be applied as a poultice or reduced to a form in which it could be mixed with cream or fat and turned into an ointment. In some regions, it is also described its use as the pre-eminent salve for burns (Allen \& Hatfield, 2004). The infusion prepared with the leaves has also been reported to have diuretic properties and can be used as ophthalmic disinfectant (Benhouda \& Yahia, 2015; Gonzáles et al., 2009), while leaves prepared with olive oil were once used as an ointment to treat haemorrhoids (Carvalho \& Morales, 2010). Despite its interest as both wild plant food and traditional medicine, as far as the authors know, studies focusing on the chemical characterization of this plant are almost inexistent, with no reports about its nutritional composition and only a few phytochemical compounds, namely three phenylpropanoids, being described so far (Viornery et al., 2000). Likewise, studies on the bioactive properties of this plant are very scarce on the literature (Benhouda \& Yahia, 2015; Benhouda et al., 2014; Bullitta, Piluzza, \& Manunta, 2013). Therefore, this work aims at the detailed chemical characterization of $U$. rupestris leaves regarding the nutritional value and phytochemical composition of samples collected in Portugal, in the same period at three different geographical locations. In addition, the bioactive potential of the hydroethanolic and decoctions extracts was also assessed in terms of its hepatotoxicity, antioxidant, anti-inflammatory and antimicrobial properties.

\section{Materials and methods}

\subsection{Samples}

Samples of Umbilicus rupestris (leaves) were harvested in January 2018 in different regions of Portugal, more specifically in the centre region (city of Viseu, $40^{\circ} 39^{\prime} 39^{\prime \prime} \mathrm{N}, 7^{\circ} 54^{\prime} 34^{\prime \prime} \mathrm{E}, 468 \mathrm{~m}$ a.s.l.), in the north inland region (near the city of Vila Real, $41^{\circ} 17^{\prime} 34^{\prime \prime} \mathrm{N}, 7^{\circ} 47^{\prime} 16^{\prime \prime}$ $\mathrm{W}, 614 \mathrm{~m}$ a.s.l.) and in the northeast region (near the city of Bragança, $41^{\circ} 54^{\prime} 04^{\prime \prime} \mathrm{N}, 6^{\circ} 44^{\prime} 22^{\prime \prime} \mathrm{W}, 669 \mathrm{~m}$ a.s.l.). The samples from Viseu, Vila Real and Bragança were denominated as UR1, UR2 and UR3, respectively.

The fresh leaves were lyophilized $\left(-49^{\circ} \mathrm{C}, 0.08 \mathrm{bar}, 48 \mathrm{~h}\right.$, FreeZone 4.5, Labconco, MO, USA) and reduced to a fine powder (20 mesh).

\subsection{Hydroethanolic and decoction extracts}

Hydroethanolic extracts were prepared by extracting $2.5 \mathrm{~g}$ of each freeze-dried sample with an ethanol:water solution $(80: 20, v / v)$ under magnetic stirring for $1 \mathrm{~h}$. After filtration through a Whatman filter paper $\mathrm{N}^{\circ} .4$, the plant residue was re-extracted and the combined filtrates were then evaporated under pressure at $40{ }^{\circ} \mathrm{C}$ (rotary evaporator Büchi R-210, Flawil, Switzerland) and subsequently lyophilized.

Decoctions were prepared using $1 \mathrm{~g}$ of freeze-dried samples and $100 \mathrm{~mL}$ of heated distilled water. The mixture was boiled for $5 \mathrm{~min}$ using a heating plate (VELP Scientific) and then filtrated through a Whatman filter paper $\mathrm{N}^{\circ}$. 4. The obtained decoctions were frozen and lyophilized to obtain a dried extract.

\subsection{Chemical composition}

\subsubsection{Nutritional value}

The proximate composition (moisture, fat, ash, proteins and carbohydrates) was determined in the freeze-dried samples, according to the AOAC methods (AOAC, 2016). The crude protein was determined by the macro-Kjeldahl method $(N \times 6.25)$ using an automatic distillation and titration unit (model Pro-Nitro-A, JP Selecta, Barcelona), the crude fat was determined by Soxhlet extraction with petroleum ether during $7 \mathrm{~h}$, and the ash content was evaluated by incineration at $550 \pm 15^{\circ} \mathrm{C}$. Total carbohydrates content was calculated by difference using the formula: Total carbohydrates $(\mathrm{g} / 100 \mathrm{~g})=100-\left(\mathrm{g}_{\text {fat }}+\mathrm{g}\right.$ ash $+g$ proteins $)$ and the energetic value was calculated according to the Atwater system using the formula: Energy $(\mathrm{kcal} / 100 \mathrm{~g})=4 \times(\mathrm{g}$ proteins $+\mathrm{g}$ carbohydrates $)+9 \times\left(\mathrm{g}_{\text {fat }}\right)$.

\subsubsection{Free sugars}

Soluble free sugars were determined on the freeze-dried plant $(1.0 \mathrm{~g})$ being extracted following a previously described methodology (Barros et al., 2013). The analyses were performed using a high performance liquid chromatography system coupled with a refraction index detector (HPLC-RI; Knauer, Smartline system 1000, Berlin, Germany) operating as previously described (Barros et al., 2013). Compounds were identified by comparison with standards and quantified by the internal standard (IS) method using melizitose. Results were recorded and processed using the Clarity 2.4 software (DataApex, Prague, Czech Republic) and expressed as $\mathrm{g}$ per $100 \mathrm{~g}$ of plant fresh weight.

\subsubsection{Organic acids}

Organic acids were extracted from the freeze-dried plant $(1.0 \mathrm{~g})$ using a previously described methodology (Barros et al., 2013) being subsequently analyzed using a ultra-fast liquid chromatography system coupled with a diode-array detector (UPLC-DAD; Shimadzu 20A series UFLC, Shimadzu Corporation, Kyoto, Japan) operating as previously described (Barros et al., 2013). Compounds were identified by comparison of retention time and spectra with those of standards (oxalic, quinic, malic, ascorbic, citric and fumaric acids, Sigma-Aldrich, St. Louis, MO, USA) and quantified based on calibration curves obtained by plotting the peak area recorded at $245 \mathrm{~nm}$ for ascorbic acid and at $215 \mathrm{~nm}$ for the remaining acids against concentration $(\mathrm{mg} / \mathrm{mL})$. The results were expressed as $\mathrm{g}$ per $100 \mathrm{~g}$ of plant fw.

\subsubsection{Fatty acids}

Fatty acids composition was determined by gas-liquid chromatography, after the extraction and derivatization to fatty acid methyl esters (FAME) according to a previously described methodology (Obodai et al., 2017). The analysis was carried out using a DANI model GC 1000 instrument equipped with a split/splitless injector set at $250{ }^{\circ} \mathrm{C}$ with a split ratio of 1:50, a flame ionization detector (FID) set at $260^{\circ} \mathrm{C}$ and a Zebron-Kame column $(30 \mathrm{~m} \times 0.25 \mathrm{~mm}$ ID $\times 0.20 \mu \mathrm{m} d f$, Phenomenex, Lisbon, Portugal). The following oven temperature program was used: initial temperature of $100^{\circ} \mathrm{C}$, held for $2 \mathrm{~min}$, then a $10^{\circ} \mathrm{C} / \mathrm{min}$ ramp to $140{ }^{\circ} \mathrm{C}, 3{ }^{\circ} \mathrm{C} / \mathrm{min}$ ramp to $190^{\circ} \mathrm{C}, 30^{\circ} \mathrm{C} / \mathrm{min}$ ramp to $260^{\circ} \mathrm{C}$ and held for $2 \mathrm{~min}$. Hydrogen was used as the carrier gas with a flow-rate of $1.1 \mathrm{~mL} /$ min, measured at $100^{\circ} \mathrm{C}$. Fatty acid identification and quantification was performed by comparing the relative retention times of FAME peaks from samples with those of standards (reference standard mixture 47,885-U, Sigma, St. Louis, MO, USA). The results were recorded and processed using the Software Clarity DataApex 4.0 Software (Prague, Czech Republic) and expressed in relative percentage of each fatty acid.

\subsubsection{Tocopherols}

Tocopherols were determined on the freeze-dried plant $(\sim 500 \mathrm{mg})$ using a high performance liquid chromatography system coupled with a fluorescence detector (HPCL-FL; Knauer, Smartline system 1000, Berlin, Germany), as previously described (Barros, Carvalho, Morais, \& 
Ferreira, 2010). The quantification of the different tocopherol isoforms $(\alpha-, \beta-, \gamma-$ and $\delta$-) was performed based on calibration curves constructed using authentic standards (Sigma, St. Louis, MO, USA) and tocol (Matreya, Pleasant Gap, PA, USA) as internal standard. The results were recorded and processed using the Clarity 2.4 software (DataApex, Prague, Czech Republic) and expressed in mg per $100 \mathrm{~g}$ plant fw.

\subsubsection{Phenolic compounds}

Phenolic compounds were determined in the hydroethanolic and decoction extracts, which were re-dissolved in methanol/water (80:20, $v / v)$ to a final concentration of $5 \mathrm{mg} / \mathrm{mL}$ and filtered using a $0.22 \mu \mathrm{m}$ disposable filter disk. The extracts were then evaluated using high performance liquid chromatography coupled with a diode-array and mass spectrometer detector (HPLC-DAD-ESI-MS/MS) operating under the conditions thoroughly described by the authors (Bessada, Barreira, Barros, Ferreira, \& Oliveira, 2016). Compounds identification was performed by comparison of retention times, UV-VIS and spectra mass of samples compounds with those of the available standards. In the case standards were not available, compounds were tentatively identified based on the fragmentation pattern and data reported in the literature. Compounds were quantified as caffeic acid, ferulic acid and quercetin3-O-glucoside by comparing the areas of the peaks recorded from samples with the calibration curves obtained from standards (200-5 $\mu \mathrm{g} / \mathrm{mL}$, Extrasynthese, Genay, France). Results were expressed in $\mathrm{mg}$ per $\mathrm{g}$ of extract.

\subsection{Bioactive properties}

\subsubsection{Evaluation of in vitro antioxidant properties}

The antioxidant activity of both the hydroethanolic and decoction extracts was determined in vitro according to the methodologies reported by the authors (Sarmento, Barros, Fernandes, Carvalho, \& Ferreira, 2015) and included the following assays: DPPH (2,2-diphenyl1-picrylhydrazyl, Alfa Aesar, Ward Hill, MA, USA) radical-scavenging activity, reducing power (measured by ferricyanide Prussian blue assay), $\beta$-carotene bleaching inhibition (assessed though the $\beta$-carotene/linoleate assay) and lipid peroxidation inhibition (assessed by the thiobarbituric acid reactive substances (TBARS) assay in porcine brain homogenates). The tested concentration of both hydroethanolic and decoction extracts ranged from 5 to $0.0195 \mathrm{mg} / \mathrm{mL}$. $\mathrm{EC}_{50}$ values (sample concentration providing $50 \%$ of antioxidant activity or 0.5 of absorbance in the case of the reducing power assay) were used to expressed the results. Trolox (Sigma-Aldrich, St. Louis, MO, USA) was used as a standard.

\subsubsection{Hepatotoxic activity}

Hepatotoxicity was evaluated using a primary cell culture prepared from porcine liver (PLP2), which was prepared according to the procedure described by the authors (Abreu et al., 2011). The tested concentration of both hydroethanolic and decoction extracts ranged from 400 to $6.5 \mu \mathrm{g} / \mathrm{mL}$. The results were measured using the Sulforhodamine $\mathrm{B}$ (SRB) method and were expressed as $\mathrm{GI}_{50}$ values (concentration that inhibits $50 \%$ of cell growth).

\subsubsection{Anti-inflammatory activity}

The anti-inflammatory activity of the hydroethanolic and decoction extracts was determined based on the nitric oxide (NO) production by a murine macrophage (RAW 264.7) cell line, induced by the addition of lipopolysaccharide (LPS). The tested concentration of both hydroethanolic and decoction extracts ranged from 400 to $6.5 \mu \mathrm{g} / \mathrm{mL}$. NO production was quantified based on nitrite concentration using the Griess Reagent System kit containing sulfanilamide, $N$-1-naphthylethylenediamine dihydrochloride and nitrite solutions following a procedure previously described by Correa et al. (2015). Dexamethasone was used as a positive control while no LPS was added in negative controls. The effect of the tested extracts in NO basal levels was also assessed by performing the assay in the absence of LPS. The results were expressed as $\mathrm{IC}_{50}$ values $(\mu \mathrm{g} / \mathrm{mL})$, corresponding to the extract concentration providing $50 \%$ inhibition of NO production.

\subsubsection{Antimicrobial activity}

The antimicrobial activity of the hydroethanolic and decoction extracts was determined against clinical isolates obtained from patients hospitalized in the Local Health Unit of Bragança and Hospital Center of Trás-os-Montes and Alto-Douro Vila Real, following the microdilution method described by the authors (Pires et al., 2018). The tested concentration of both hydroethanolic and decoction extracts ranged from 20 to $0.156 \mathrm{mg} / \mathrm{mL}$. The tested microorganisms included Gram-positive (Enterococcus faecalis, Listeria monocytogenes and methicillin-resistant Staphylococcus aureus) and Gram-negative bacteria (Escherichia coli, Klebsiella pneumoniae, Morganela morganii, Proteus mirabilis and Pseudomonas aeruginosa). The measurement of the minimum inhibitory concentration (MIC) was determined by a colorimetric microbial viability assay based on the reduction of iodonitrotetrazolium chloride $(0.2 \mathrm{mg} / \mathrm{mL})$. The minimum bactericidal inhibitory concentration (MBC) was evaluated by plating a loopful of the content of the microwells that did not exhibited coloration in the MIC assay. Ampicillin and Imipenem were used as negative controls for Gram-negative bacteria while Vancomycin and Ampicillin were used for Gram-positive bacteria. Culture broth (Muller Hinton Broth added with 5\% dimethylsulfoxide) inoculated with each bacteria was used as positive control.

\subsection{Statistical analysis}

Results were expressed as mean \pm standard deviation (SD) of the analysis of three samples, each being assayed in triplicate. The statistical analysis was by using SPSS v. 23.0 software and comprised a onevariance analysis (ANOVA) followed by Tukey's HSD test $(\alpha=0.05)$.

\section{Results and discussion}

\subsection{Chemical composition}

Considering that a range of different factors are known to affect the phytochemical profile of plants, including the geographical origin with its inherent variation of climatic conditions and soil characteristics, harvesting period, plant part and genetic factors, among others, in this study samples were collected from three distinct locations to account for geographical origin variability. The samples were all collected at the same harvesting period, with at least $300 \mathrm{~g}$ of young leaves being picked from each region (Viseu, UR1; Vila Real, UR2 and Bragança, UR3).

The results obtained for the proximal composition, free soluble sugars and organic acids is presented in Table 1 . As expected due to the crassulacean acid metabolism (CAM) characteristic of succulent plants like $U$. rupestris, all samples presented a very high moisture content. As previously mentioned, CAM is characterized by the opening of stomas during the night and closure during most part of the day, allowing for a minimum loss of water (Geydan \& Melgarejo, 2005). For the macronutrients, in all samples carbohydrates were found to be the major group, followed by proteins and ash, with lipids being the less abundant. Statistically significant differences $(p<0.05)$ were found for all groups, with exception for moisture. This can possibly be ascribed to environmental factors, such as climate and soil conditions. In particular, cold and hydric stress, can promote changes in the chemical composition of plants (Amaral et al., 2006; Machado et al., 2013). Observing the meteorological data in December for the three locations, Viseu presented the highest mean values of minimum temperature, maximum temperature and rainfall, followed by Vila Real, with Bragança presenting the lower minimum and rainfall values (de Clima, 2017) (Supplementary material, Fig. S1). 
Table 1

Nutritional value, energetic value, free sugars and organic acids of the studied Umbilicus rupestris samples (mean $\pm \mathrm{SD}, n=3$ ).

\begin{tabular}{|c|c|c|c|}
\hline & UR1 & UR2 & UR3 \\
\hline \multicolumn{4}{|l|}{ Nutritional value } \\
\hline Moisture & $93 \pm 1^{\mathrm{a}}$ & $94.6 \pm 0.5^{\mathrm{a}}$ & $93.6 \pm 0.1^{\mathrm{a}}$ \\
\hline Ash (g/100g fw) & $0.91 \pm 0.01^{\mathrm{a}}$ & $0.61 \pm 0.07^{\mathrm{b}}$ & $0.83 \pm 0.05^{\mathrm{a}}$ \\
\hline Proteins $(\mathrm{g} / 100 \mathrm{~g} \mathrm{fw})$ & $1.83 \pm 0.06^{\mathrm{a}}$ & $1.60 \pm 0.05^{\mathrm{b}}$ & $1.35 \pm 0.01^{\mathrm{c}}$ \\
\hline Lipids (g/100 g fw) & $0.255 \pm 0.002^{\mathrm{a}}$ & $0.203 \pm 0.006^{\mathrm{b}}$ & $0.17 \pm 0.02^{\mathrm{c}}$ \\
\hline $\begin{array}{l}\text { Carbohydrates (g/100g } \\
\text { fw) }\end{array}$ & $3.90 \pm 0.03^{b}$ & $2.94 \pm 0.09^{c}$ & $4.03 \pm 0.05^{\mathrm{a}}$ \\
\hline Energy (kcal/100 g fw) & $25.2 \pm 0.1^{\mathrm{a}}$ & $20.0 \pm 0.2^{\mathrm{c}}$ & $23.0 \pm 0.1^{\mathrm{b}}$ \\
\hline \multicolumn{4}{|l|}{$\begin{array}{l}\text { Free sugars }(g / 100 g \\
\quad f w)\end{array}$} \\
\hline Manose & $0.902 \pm 0.01^{\mathrm{a}}$ & $0.51 \pm 0.02^{\mathrm{c}}$ & $0.78 \pm 0.06^{\mathrm{b}}$ \\
\hline Sucrose & $0.082 \pm 0.002^{\mathrm{a}}$ & $0.020 \pm 0.002^{c}$ & $0.073 \pm 0.003^{b}$ \\
\hline Total free sugars & $0.98 \pm 0.01^{\mathrm{a}}$ & $0.53 \pm 0.03^{c}$ & $0.85 \pm 0.06^{\mathrm{b}}$ \\
\hline \multicolumn{4}{|l|}{$\begin{array}{l}\text { Organic acids }(g / 100 g \\
f w)\end{array}$} \\
\hline Oxalic acid & $0.48 \pm 0.01^{\mathrm{a}}$ & $0.33 \pm 0.01^{\mathrm{b}}$ & $0.27 \pm 0.01^{\mathrm{c}}$ \\
\hline Malic acid & $0.210 \pm 0.005^{\mathrm{b}}$ & $0.215 \pm 0.001^{\mathrm{b}}$ & $0.421 \pm 0.002^{\mathrm{a}}$ \\
\hline Ascorbic acid & $0.021 \pm 0.001^{\mathrm{a}}$ & $0.008 \pm 0.001^{c}$ & $0.013 \pm 0.001^{b}$ \\
\hline Citric acid & $0.334 \pm 0.001^{\mathrm{b}}$ & $0.375 \pm 0.002^{\mathrm{a}}$ & $0.21 \pm 0.01^{\mathrm{c}}$ \\
\hline Fumaric acid & $\operatorname{tr}$ & $\operatorname{tr}$ & $\operatorname{tr}$ \\
\hline Total organic acids & $1.04 \pm 0.01^{\mathrm{a}}$ & $0.93 \pm 0.01^{\mathrm{b}}$ & $0.92 \pm 0.01^{\mathrm{b}}$ \\
\hline
\end{tabular}

tr - traces; fw - fresh weigh. Different letters in the same row mean significant differences $(p<0.05)$. Samples were collected from different regions, UR1:Viseu, UR2: Vila Real, UR3: Bragança.

Only two soluble sugars were identified in the three samples, namely manose and sucrose, with total free sugars ranging from 0.53 to $0.98 \mathrm{~g}$ per $100 \mathrm{~g}$ of fresh plant (Table 1). Moreover, the leaves of $U$. rupestris showed a low energetic value, therefore being adequate to be included in low carb diets.

Regarding organic acids, four compounds were identified, namely oxalic, malic, ascorbic and citric acids, although trace levels of fumaric acid were also detected in the three analysed $U$. rupestris leaves (Table 1). As referred, although $U$. rupestris can behave as a normal C-3 plant, it can change to CAM in water stress conditions, which is usual to occur in this plant since it mainly grows on walls, cliffs and rock-faces with very few soil to retain water (Daniel et al., 1985). A feature of CAM plants is that during the night they produce oxaloacetate which is rapidly converted to malate, thus explaining that these two acids were detected as major organic acids in samples UR1 and UR3. Interestingly, samples UR1 and UR2 presented higher levels of malic acid compared to citric acid, while the opposite was observed in UR3. According to Chen and Nose (2004) the transport of malate to the vacuoles is associate to CAM metabolism and requires the use of energy, therefore implying the consumption of citric acid and explaining the lower level of this acid in the sample UR3, which was the one with higher malic acid content. During the day, malate is decarboxylated and the $\mathrm{CO}_{2}$ is re-fixed via the Calvin cycle, therefore causing a diurnal fluctuation in acid content of the leaves (Daniel et al., 1985). For this reason, the collection hour of the samples was carefully chosen, with all being harvested in the afternoon (between 16:00 and 17:00H). Even so, statistically significant differences were found to occur among the three samples, which can be due to other environmental or even genetic factors.

Determination of plants fatty acids composition enables a more detailed evaluation of the nutrients composition and potential benefits related to their consumption. The fatty acid profile of $U$. rupestris leaves is shown in Table 2, evidencing that a total of 24 fatty acids were identified, with the two major compounds being the essential fatty acids $\alpha$-linolenic and linoleic acids. In the three evaluated samples, polyunsaturated fatty acids (PUFA) were the major group, with large predominance of $\omega-3$ over $\omega-6$ fatty acids. An adequate intake of $\omega-3$ fatty acids is of great importance as they can influence inflammation, blood pressure, vasoconstriction, blood clotting and immune function,
Table 2

Composition of fatty acids and of tocopherols of the studied Umbilicus rupestris samples (mean $\pm \mathrm{SD}, n=3$ ).

\begin{tabular}{llll} 
& UR1 & UR2 & UR3 \\
\hline Fatty acids & & & \\
C8:0 & $0.043 \pm 0.001^{\mathrm{a}}$ & $0.025 \pm 0.001^{\mathrm{c}}$ & $0.029 \pm 0.001^{\mathrm{b}}$ \\
C10:0 & $0.024 \pm 0.001^{\mathrm{a}}$ & $0.023 \pm 0.002^{\mathrm{a}}$ & $0.017 \pm 0.001^{\mathrm{b}}$ \\
C11:0 & $0.23 \pm 0.01^{\mathrm{a}}$ & $0.18 \pm 0.01^{\mathrm{b}}$ & $0.26 \pm 0.03^{\mathrm{a}}$ \\
C12:0 & $0.043 \pm 0.001^{\mathrm{c}}$ & $0.070 \pm 0.001^{\mathrm{a}}$ & $0.056 \pm 0.002^{\mathrm{b}}$ \\
C13:0 & $0.169 \pm 0.004^{\mathrm{b}}$ & $0.38 \pm 0.03^{\mathrm{a}}$ & $0.12 \pm 0.01^{\mathrm{c}}$ \\
C14:0 & $0.48 \pm 0.007^{\mathrm{b}}$ & $0.77 \pm 0.02^{\mathrm{a}}$ & $0.76 \pm 0.05^{\mathrm{a}}$ \\
C14:1 & $0.153 \pm 0.001^{\mathrm{b}}$ & $0.275 \pm 0.004^{\mathrm{a}}$ & $0.086 \pm 0.003^{\mathrm{c}}$ \\
C15:0 & $0.068 \pm 0.005^{\mathrm{b}}$ & $0.079 \pm 0.003^{\mathrm{a}}$ & $0.065 \pm 0.001^{\mathrm{b}}$ \\
C16:0 & $10.6 \pm 0.8^{\mathrm{b}}$ & $12.0 \pm 0.5^{\mathrm{a}}$ & $11.0 \pm 0.2^{\mathrm{ab}}$ \\
C16:1 & $1.07 \pm 0.03^{\mathrm{a}}$ & $0.98 \pm 0.04^{\mathrm{b}}$ & $0.61 \pm 0.04^{\mathrm{c}}$ \\
C17:0 & $0.128 \pm 0.001^{\mathrm{b}}$ & $0.114 \pm 0.008^{\mathrm{c}}$ & $0.201 \pm 0.001^{\mathrm{a}}$ \\
C18:0 & $1.6 \pm 0.2^{\mathrm{a}}$ & $0.80 \pm 0.02^{\mathrm{c}}$ & $1.06 \pm 0.02^{\mathrm{b}}$ \\
C18:1n9 & $0.641 \pm 0.002^{\mathrm{b}}$ & $0.50 \pm 0.02^{\mathrm{c}}$ & $0.69 \pm 0.02^{\mathrm{a}}$ \\
C18:2n6 & $18.3 \pm 0.6^{\mathrm{b}}$ & $17.9 \pm 0.9^{\mathrm{b}}$ & $21.0 \pm 0.3^{\mathrm{a}}$ \\
C18:3n3 & $62 \pm 2$ & $61 \pm 2^{\mathrm{ab}}$ & $58.9 \pm 0.6^{\mathrm{b}}$ \\
C20:0 & $0.68 \pm 0.04^{\mathrm{a}}$ & $0.54 \pm 0.04^{\mathrm{b}}$ & $0.48 \pm 0.02^{\mathrm{b}}$ \\
C20:1 & $0.037 \pm 0.001^{\mathrm{b}}$ & $0.047 \pm 0.001^{\mathrm{a}}$ & $0.028 \pm 0.001^{\mathrm{c}}$ \\
C20:2 & $0.079 \pm 0.004^{\mathrm{b}}$ & $0.105 \pm 0.005^{\mathrm{a}}$ & $0.077 \pm 0.003^{\mathrm{b}}$ \\
C21:0 & $18 \pm 1^{\mathrm{a}}$ & $18.9 \pm 0.7^{\mathrm{a}}$ & $18.0 \pm 0.3^{\mathrm{a}}$ \\
C20:4n6 & $1.90 \pm 0.02^{\mathrm{a}}$ & $1.79 \pm 0.05^{\mathrm{b}}$ & $1.41 \pm 0.01^{\mathrm{c}}$ \\
C20:3n3 & $80 \pm 1^{\mathrm{a}}$ & $79.2 \pm 0.8^{\mathrm{a}}$ & $80.6 \pm 0.3^{\mathrm{a}}$ \\
C22:0 & $0.046 \pm 0.004^{\mathrm{a}}$ & $0.035 \pm 0.003^{\mathrm{b}}$ & $0.028 \pm 0.002^{\mathrm{c}}$ \\
C23:0 & $0.449 \pm 0.004^{\mathrm{c}}$ & $0.60 \pm 0.02^{\mathrm{a}}$ & $0.56 \pm 0.02^{\mathrm{b}}$ \\
C24:0 & $0.151 \pm 0.009^{\mathrm{a}}$ & $0.11 \pm 0.01^{\mathrm{b}}$ & $0.121 \pm 0.001^{\mathrm{b}}$ \\
SFA (\%) & $1.27 \pm 0.09^{\mathrm{a}}$ & $1.2 \pm 0.1^{\mathrm{a}}$ & $0.92 \pm 0.05^{\mathrm{b}}$ \\
MUFA (\%) & $1.25 \pm 0.09^{\mathrm{c}}$ & $1.83 \pm 0.03^{\mathrm{b}}$ & $2.038 \pm 0.001^{\mathrm{a}}$ \\
PUFA (\%) & $0.926 \pm 0.002^{\mathrm{a}}$ & $0.9 \pm 0.1^{\mathrm{b}}$ & $0.95 \pm 0.02^{\mathrm{a}}$ \\
Cocop & &
\end{tabular}

Tocopherols $(\mu \mathrm{g} / \mathbf{1 0 0} \mathrm{g}$ fw)

$\begin{array}{ll}\alpha \text {-Tocopherol } & 636 \pm 0.006^{\mathrm{b}} \\ \beta \text {-Tocopherol } & 42 \pm 0.001^{\mathrm{a}} \\ \gamma \text {-Tocopherol } & 70 \pm 0.001^{\mathrm{c}} \\ \begin{array}{l}\delta \text {-Tocopherol } \\ \text { Total tocopherols }(\mu \mathrm{g} /\end{array} & 36 \pm 0.002^{\mathrm{c}} \\ \quad \mathbf{1 0 0} \mathbf{g ~ f w}) & \end{array}$

$552 \pm 0.001^{\mathrm{c}}$

$20 \pm 0.001^{\mathrm{c}}$

$300 \pm 0.001^{\mathrm{a}}$

$180 \pm 0.001^{\mathrm{a}}$

$700 \pm 0.001^{\mathrm{a}}$

$25 \pm 0.001^{\mathrm{b}}$

$152 \pm 0.001^{\mathrm{b}}$

$101 \pm 0.003^{\mathrm{b}}$

$1050 \pm 0.01^{\mathrm{a}} \quad 980 \pm 0.01^{\mathrm{b}}$

Caprylic acid (C8:0); Capric acid (C10:0); Undecanoic acid (C11:0); Lauric acid (C12:0); Tridecanoic acid (C13:0); Myristic acid (C14:0); Myristoleic acid (C14:1); Pentadecanoic acid (C15:0); Palmitic acid (C16:0); Palmitoleic acid (C16:1); Heptadecanoic acid (C17:0); Stearic acid (C18:0); Oleic acid (C18:1n9c); Linoleic acid (C18:2n6c); $\alpha$-Linolenic acid (C18:3n3); Arachidic acid (C20:0); Eicosenoic acid (C20:1c); cis-11,14-Eicosadienoic acid (C20:2c); Heneicosanoic acid (C21:0); Arachidonic acid (C20:4n6); cis-11,14,17Eicosatrienoic acid (C20:3n3); Behenic acid (C22:0); Tricosanoic acid (C23:0); Lignoceric acid (C24:0); SFA: Saturated fatty aids; MUFA: Monounsaturated fatty acids; PUFA: Polyunsaturated fatty acids. Different letters in the same row mean significant differences $(p<0.05)$.

among other processes (Calder, 2015). Also, dietary consumption of $\omega$ 3 PUFA is generally recommended in international guidelines for the general population to prevent the occurrence of cardiovascular diseases (CVD) since several large-scale randomized clinical trials have been showing that dietary intake of these compounds improves the prognosis of patients with CVD (Endo \& Arita, 2016). The qualitative profile of the three samples was found to be identical and, although the content of some individual fatty acids was statistically different, no differences were observed among samples regarding the total PUFA and total saturated fatty acids (SFA) contents $(p>0.05)$.

Vitamin $\mathrm{E}$ is a term used to designate a family of related compounds, namely $\alpha$-, $\beta-, \gamma$ - and $\delta$-tocopherols and tocotrienols, which present a common structure with a chromanol ring and an isoprenic side chain and whose biological activities are mainly related to their antioxidant activity, enabling them to inhibit lipid peroxidation in biological membranes (Tucker \& Townsend, 2005; Woollard \& Indyk, 2003). Vitamin $\mathrm{E}$ composition of the studied samples is shown in Table 2 were it can be observed that $\alpha$-tocopherol was the major compound, followed by $\gamma$ - and $\delta$-tocopherols. All four isoforms of tocopherol were present in 
Hydroethanolic extract
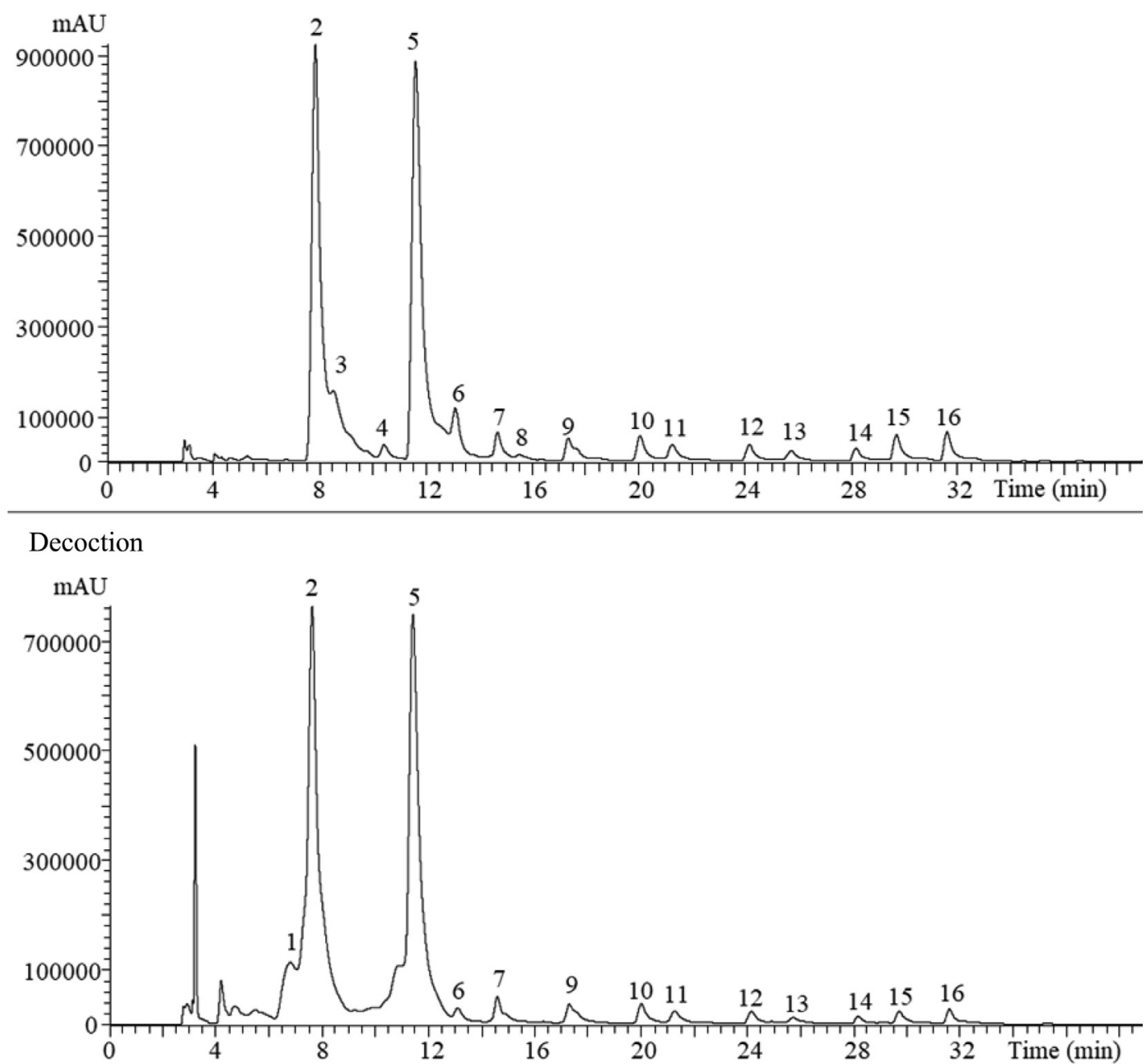

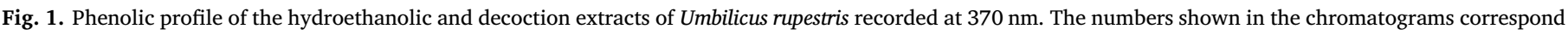
to the compounds identified in Table 3 .

the three samples from different geographical origins, although statistically significant differences were observed among them.

The characterization of $U$. rupestris phenolic compounds profile was performed by HPLC-DAD-ESI/MS (Fig. 1). Chromatographic data regarding the retention time, $\lambda_{\max }$, pseudomolecular ion, main fragment ions in $\mathrm{MS}^{2}$, tentative identification and quantification of the phenolic compounds are presented in Table 3. To the best of the authors knowledge, so far only one study has been performed regarding the phenolic profile of this species (Table 3), reporting the presence of three compounds, 2-O-caffeoyl malate, isoquercitrin and venusol (Viornery et al., 2000). In this study, $U$. rupestris sample revealed the presence of sixteen compounds, allowing us to confirm the presence of venusol in this species, and additionally describing the presence of three phenolic acids (hydroxycinnamic derivatives) and twelve flavonoids (flavonol and flavone glycoside derivatives). Compounds 3 (caffeic acid) and 8 (ferulic acid) were positively identified in comparison with the commercial standards. Compound $4\left([\mathrm{M}-\mathrm{H}]^{-}\right.$at $m / z$ 355) revealed $162 \mathrm{u}$ (glycosil moiety) higher than peak 8 , being identified as ferulic acid hexoside. Compound $6\left([\mathrm{M}-\mathrm{H}]^{-}\right.$at $m / z$ 323) was identified as venusol, taking into account its UV spectra and pseudomolecular ion pattern previously described for this compound by Viornery et al. (2000).

The remaining compounds were identified as flavonol glycoside derivatives: quercetin ( $\lambda$ max around $353 \mathrm{~nm}$, and an $\mathrm{MS}^{2}$ fragment at $m / z 301$ ), isorhamnetin ( $\lambda_{\max }$ around $358 \mathrm{~nm}$, and an $\mathrm{MS}^{2}$ fragment at $m / z$ 315), myricetin ( $\lambda_{\max }$ around $356 \mathrm{~nm}$, and an $\mathrm{MS}^{2}$ fragment at $m / z$ $317)$ and flavone glycoside derivatives: chrysoeriol $\left(\lambda_{\max }\right.$ around $354 \mathrm{~nm}$, and an $\mathrm{MS}^{2}$ fragment at $\mathrm{m} / z$ 299). Compounds 1 and 2 presented the same pseudomolecular ion $\left([\mathrm{M}-\mathrm{H}]^{-}\right.$at $\left.m / z 655\right)$, with $\mathrm{MS}^{2}$ fragments revealing the alternative loss of glucuronyl $(\mathrm{m} / \mathrm{z}$ at 479 ; $-176 \mathrm{u})$ and hexosyl $(\mathrm{m} / \mathrm{z}$ at $317 ;-162 \mathrm{u}$ ) residues, indicating location of each residue on different positions of the aglycone, being both identified as myricetin- $O$-glucuroside- $O$-hexoside. Similarly, compound $5\left([\mathrm{M}-\mathrm{H}]^{-}\right.$at $m / z$ 639) was identified as quercetin-O-glucuroside- $O$ hexoside. Compound $7\left([\mathrm{M}-\mathrm{H}]^{-}\right.$at $\left.m / z 741\right)$ presented $86 \mathrm{u}$ (malonyl moiety) higher then compounds 1 and 2 , being tentatively assigned as myricetin- $O$-malonylglucuroside- $O$-hexoside. The mass characteristics of peak $9\left([\mathrm{M}-\mathrm{H}]^{-}\right.$at $\left.m / z 725\right)$ and $11\left([\mathrm{M}-\mathrm{H}]^{-}\right.$at $\left.m / z 739\right)$ indicated that it corresponds to isorhamnetin derivatives, bearing in the first compound a pentosyl moiety (peak 9) and a deoxyhexoside in the second compound (peak 11), and a further loss in both peaks of a deoxyhexosyl-pentoside residues. The observation of $\mathrm{MS}^{2}$ fragments at $m / z 593(-132$ and $146 u)$ and $315(-146+132 u)$, also indicated the alternative loss of each of the group of sugar moieties, respectively, pointing to their location on different positions of the aglycone. Thus, these compounds were tentatively identified as isorhamnetin-O-pentoside- $O$-(deoxyhexosyl-pentoside) and isorhamnetin- $O$-deoxyhexoside$O$-(deoxyhexosyl-pentoside), respectively. Similarly, compounds 10 $\left([\mathrm{M}-\mathrm{H}]^{-}\right.$at $\left.m / z 709\right)$ and $12\left([\mathrm{M}-\mathrm{H}]^{-}\right.$at $\left.m / z 723\right)$ were tentatively identified as chrysoeriol- $O$-pentoside- $O$-(deoxyhexosyl-pentoside) and 


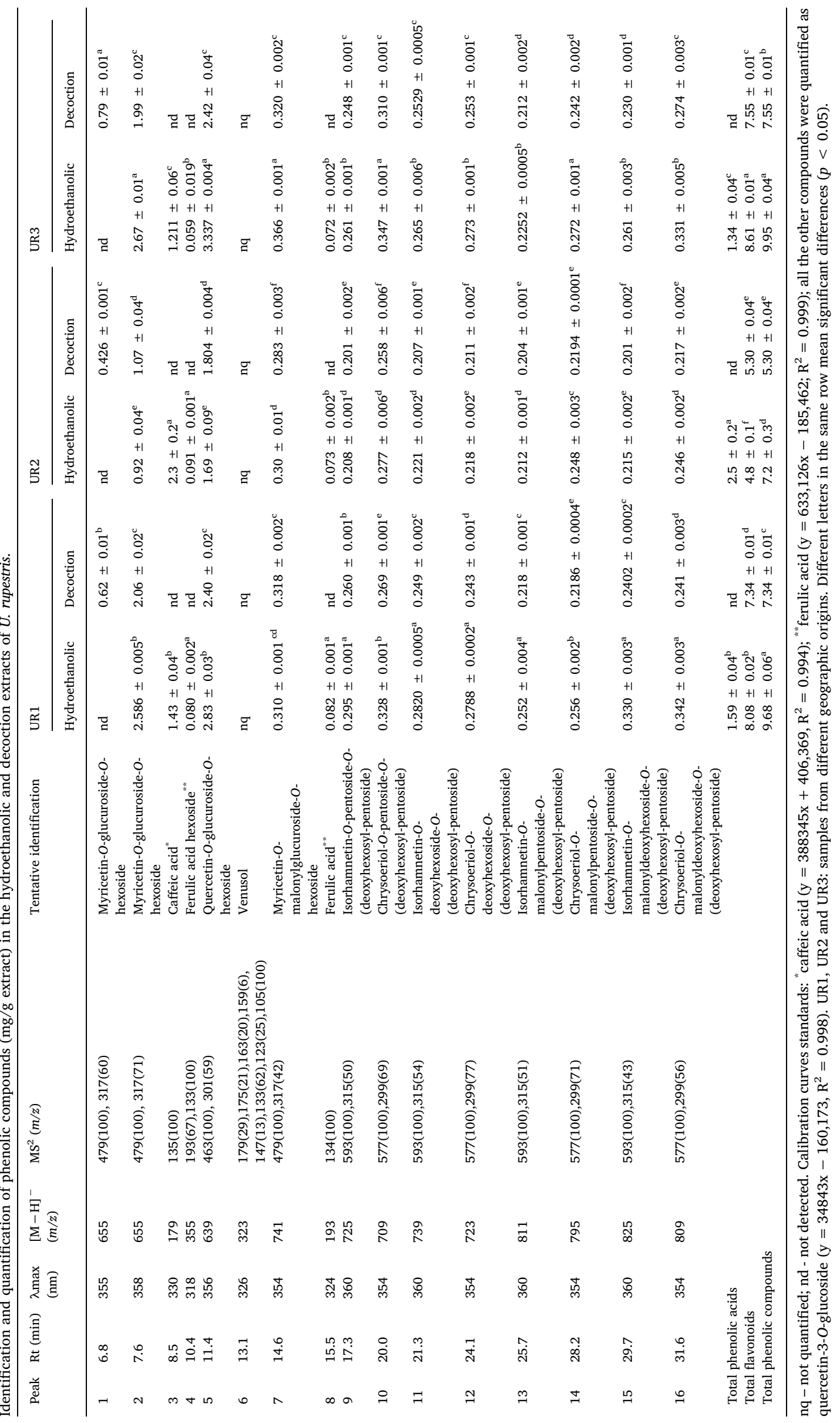


chrysoeriol-O-deoxyhexoside-O-(deoxyhexosyl-pentoside), respectively.

Compounds $13\left([\mathrm{M}-\mathrm{H}]^{-}\right.$at $\left.m / z 811\right)$ and $15\left([\mathrm{M}-\mathrm{H}]^{-}\right.$at $m / z$ $825)$ presented $86 \mathrm{u}$ (malonyl moiety) higher then compounds 9 and 11 , being tentatively assigned as isorhamnetin- $O$-malonylpentoside- $O$ (deoxyhexosyl-pentoside) and isorhamnetin- $O$-malonyldeoxyhexoside$O$-(deoxyhexosyl-pentoside), respectively. Taking into account these findings, compounds $14\left([\mathrm{M}-\mathrm{H}]^{-}\right.$at $\left.m / z 795\right)$ and $16\left([\mathrm{M}-\mathrm{H}]^{-}\right.$at $m /$ $z$ 809) were also identified as having malonyl residues (86 u) of compounds 10 and 12, thus being tentatively assigned as chrysoeriol-Omalonylpentoside- $O$-(deoxyhexosyl-pentoside) and chrysoeriol-O-malonyldeoxyhexoside- $O$-(deoxyhexosyl-pentoside), respectively.

In general, hydroethanolic extracts presented higher amounts of phenolic compounds in comparison with decoctions. These last extracts presented only flavonoid compounds with phenolic acids being absent, possibly because of degradation during the heating process. Myricetin$O$-glucuroside- $O$-hexoside (compound 2) and quercetin-O-glucuroside$O$-hexoside (compound 5) were the most abundant compounds found in all samples and also considering both extracts. Comparing the three samples collected in the same period, but in different geographical locations, UR2 samples presented a statistically significant lower value of total phenolic compounds, when compared to UR1 and UR3 samples, which presented both a similar value. As mentioned, Viseu (UR1) and Bragança (UR3) regions presented, respectively, the highest and lowest mean values of minimum temperature, maximum temperature and rainfall, therefore suggesting that these parameters were not the most relevant in what concerns phenolic compounds composition. The quantitative difference observed for the Vila Real (UR2) sample may thus be explained by other factors such as soil composition and exposure to sunlight, or even due to genetic differences.

\subsection{Bioactive properties of $U$. rupestris extracts}

The results of the antioxidant activity assays obtained for the two extracts (hydroethanolic and decoction) prepared with the plants harvested from different locations, are shown in Table 4 . As it can be observed, significant differences were found among the samples as well as between extraction methods. Independently of the assay considered, and for the three samples, better results were obtained for the hydroethanolic extracts as consistently this extraction method gave the lowest values of $\mathrm{EC}_{50}$. This can possibly be ascribed to the presence of phenolic acids in all the hydroethanolic extracts comparatively to the respective decoction extracts where these compounds were not detected (Fig. 1 and Table 3). Moreover, for UR1 and UR3 samples, the content of flavonoids was higher in the hydroethanolic extract in comparison to the decoction, thus suggesting an influence of $U$. rupestris flavonoids on the antioxidant activity properties of these extracts. Likewise, when comparing the results obtained for the hydroethanolic extracts of the three samples, UR2 was the one that presented the best results for the DPPH scavenging assay $(1.39 \mathrm{mg} / \mathrm{mL}$ compared to $2.08 \mathrm{mg} / \mathrm{mL}$ and $2.7 \mathrm{mg} / \mathrm{mL}$ for UR3 and UR1, respectively), which can possibly be related to its much higher content in caffeic acid ( $2.3 \mathrm{mg} / \mathrm{g}$ extract) compared to UR1 and UR2 (1.4 and $1.2 \mathrm{mg} / \mathrm{g}$ extract, respectively). In previous studies, caffeic acid has been shown to be an effective antioxidant in different antioxidant assays, showing higher DPPH radical scavenging activity then butylated hydroxyanisole (BHA), $\alpha$-tocopherol and trolox and higher reducing power compared to butylated hydroxytoluene, BHA, $\alpha$-tocopherol, and Trolox (Gülçin, 2006). Overall, UR1 and UR2 hydroethanolic were the samples that revealed the highest antioxidant activity, which could be related to their higher content in phenolic compounds.

Until the present date, only a few studies have been conducted on the antioxidant properties of $U$. rupestris. Piluzza and Bullitta (2011) evaluated the antioxidant activity by means of $\mathrm{ABTS}^{+}$and DPPH radical scavenging assays of twenty-four plant species of traditional ethnoveterinary medicine in the Mediterranean region and found $U$. rupestris as being among the seven plants that showed the highest antioxidant activity. The authors evaluated an extract obtained from the whole plant extracted with a mixture of acetone/water (7:3) and reported a value for the DPPH assay of $36.22 \pm 2.61 \mathrm{mmol}$ Trolox equivalents/100 g dry weight. Bullitta et al. (2013) evaluated the cellular antioxidant capability of eleven Mediterranean plant species related to ethnobotanic traditions, including $U$. rupestris, by assessing the capacity of inhibiting the formation of intracellular reactive oxygen species (ROS) in primary human umbilical vein endotelial cord blood cells (HUVEC) and in undifferentiated human promyelocytic leukemia cell-line (HL-60) as well as determining their antioxidant activity by chemical in-vitro assays (DPPH and ABTS). The extract of the whole $U$. rupestris plant prepared in dimethylsulfoxide (DMSO) showed a moderate attenuation of ROS generation in cell-culture, although being less effective in the endothelial cells compared to the promyelocytic leukemic cell-line, and presented an $\mathrm{EC}_{50}$ value of $47.4 \pm 1.22 \mu \mathrm{g} / \mathrm{mL}$ in the DPPH radical scavenging assay (Bullitta et al., 2013).

Considering the described usage of $U$. rupestris leaves in traditional medicine, the prepared extracts were also evaluated for their anti-inflammatory properties, besides their cytotoxic potential in non-tumour cells. As it can be observed in Table 4, none of the extracts presented toxicity towards the liver primary cell culture (PLP2). Similar results have been reported in previous works, since the DMSO extract of $U$. rupestris whole plant $(50 \mu \mathrm{g} / \mathrm{mL})$ also did not show any putative toxic effect in HL-60 and HUVEC cells (Bullitta et al., 2013). Also, in acute toxicity studies carried out in vivo on Wistar rats, the median lethal dose

Table 4

Antioxidant activity, hepatotoxicity and anti-inflammatory activity of the hydroethanolic and decoction extracts of $U$. rupestris (mean \pm SD, $n=3$ ).

\begin{tabular}{|c|c|c|c|c|c|c|}
\hline & \multicolumn{2}{|l|}{ UR1 } & \multicolumn{2}{|l|}{ UR2 } & \multicolumn{2}{|l|}{ UR3 } \\
\hline \multicolumn{7}{|c|}{ Antioxidant activity $\left(\mathrm{EC}_{50} \mathrm{mg} / \mathrm{mL}\right)$} \\
\hline Ferricyanide/Prussian blue ${ }^{* * *}$ & $0.422 \pm 0.002^{\mathrm{f}}$ & $1.26 \pm 0.08^{\mathrm{d}}$ & $0.746 \pm 0.008^{\mathrm{e}}$ & $2.49 \pm 0.06^{\mathrm{b}}$ & $1.57 \pm 0.02^{\mathrm{c}}$ & $2.57 \pm 0.05^{\mathrm{a}}$ \\
\hline$\beta$-carotene/linoleate" & $0.55 \pm 0.03^{\mathrm{d}}$ & $2.1 \pm 0.2^{\mathrm{c}}$ & $0.46 \pm 0.03^{\mathrm{d}}$ & $3.6 \pm 0.2^{\mathrm{a}}$ & $0.55 \pm 0.02^{\mathrm{d}}$ & $3.3 \pm 0.3^{\mathrm{b}}$ \\
\hline TBARs ${ }^{*}$ & $0.155 \pm 0.005^{\mathrm{e}}$ & $0.22 \pm 0.03^{\mathrm{c}}$ & $0.18 \pm 0.01^{\mathrm{d}}$ & $0.41 \pm 0.02^{\mathrm{a}}$ & $0.12 \pm 0.01^{\mathrm{f}}$ & $0.35 \pm 0.02^{b}$ \\
\hline \multicolumn{7}{|l|}{ Hepatotoxicity $\left(\mathrm{GI}_{50} \mu \mathrm{g} / \mathrm{mL}\right)$} \\
\hline NO-production ${ }^{* * * * *}$ & $>400$ & $>400$ & $>400$ & $>400$ & $>400$ & $>400$ \\
\hline
\end{tabular}

$\mathrm{EC}_{50}$ : extract concentration corresponding to ${ }^{*} 50 \%$ of antioxidant activity or ${ }^{* *} 0.5$ of absorbance in the reducing power assay. Trolox EC 50 values: $42 \mu \mathrm{g} / \mathrm{mL}$ (DPPH scavenging activity), $41 \mu \mathrm{g} / \mathrm{mL}$ (reducing power), $18 \mu \mathrm{g} / \mathrm{mL}$ ( $\beta$-carotene bleaching inhibition) and $23 \mu \mathrm{g} / \mathrm{mL}$ (TBARS inhibition). GI 50 : extract concentration responsible for $50 \%$ inhibition of growth in a primary culture of liver cells (PLP2). GI 50 values for Ellipticine (positive control): $3 \mu \mathrm{g} / \mathrm{mL}^{*}{ }^{* * *} \mathrm{EC} 50$ values correspond to the extract concentration achieving $50 \%$ of the inhibition of NO-production. $\mathrm{EC}_{50}$ values for dexamethasone (positive control): $16 \mu \mathrm{g} / \mathrm{mL}$. UR1, UR2 and UR3: samples from different geographic origins. Different letters in the same row mean significant differences $(p<0.05)$. 
( $\mathrm{LD}_{50}$ ) of the methanolic extract of $U$. rupestris was found to be higher than the maximum concentration tested ( $2 \mathrm{~g} / \mathrm{kg}$ body weight), with this dose causing neither death or signs of toxic manifestations on the treated rats (Benhouda \& Yahia, 2015). Regarding the anti-inflammatory properties, for the range of tested concentrations (up to $400 \mu \mathrm{g} / \mathrm{mL}$ ) the results indicated the absence of activity in LPS-activated murine macrophages since no decrease of nitric oxide levels was observed (Table 4). Nevertheless, in previous works Benhouda and Yahia (2015) reported that the methanolic extract of $U$. rupestris leaves (100 and $200 \mathrm{mg} / \mathrm{kg}$ rat body weight) significantly inhibited, in a dose dependent manner, the inflammation induced in Wistar rats paws by the subcutaneous administration of carrageenan, chemical mediators (histamine and serotonin) and formalin. The authors suggested that the anti-inflammatory activity of the extract could be due to the inhibition of inflammation mediators, inhibition of cyclooxygenase and prostaglandin synthesis or inhibition of leukocytes migration. Therefore, the absence of activity in the present study can be either due to the low range of concentrations tested or to the selected assay, since the mechanism of action is different from the tested one, which can lay behind the plant's anti-inflammatory activity. In addition, other compounds present in the leaves of $U$. rupestris, namely the polysaccharide fraction, could also possibly support the empiric use of the plant for its antiinflammatory properties. Although scarce studies have been carried out with plants from the Crassulaceae family, Sendl, Mulinacci, Vincieri, and Wagner (1993) have showed that two major rhamnogalacturonan polysaccharides isolated from the leaves of Sedum telephium, a succulent plant from the mentioned family also used in traditional medicine to treat skin inflammation, eczemas, wounds and burns, showed a high anti-inflammatory and immunological activity.

Table 5 shows the results of the antimicrobial activity of the hydroethanolic and decoction extracts of $U$. rupestris leaves against three Gram-positive and five Gram-negative multi-resistant pathogenic strains, isolated from hospitalized patients. The results showed that, in the tested concentrations $(20-0.156 \mathrm{mg} / \mathrm{mL})$, both extracts were ineffective against $P$. mirabilis and $P$. aeruginosa, however being active or moderately active against the remaining bacteria. Although some variability was found regarding extracts and samples from different geographical origins, in general, decoction extracts were more effective compared to hydroethanolic extracts, with the exception of UR3 hydroethanolic extract against $K$. pneumoniae, UR2 hydroethanolic extract against MRSA and L. monocytogenes. The lowest MIC values $(5 \mathrm{mg} / \mathrm{mL})$ were obtained against the Gram-negative $E$. coli and the Gram-positive L. monocytogenes. Curiously, in general, comparing the results obtained for the samples collected in three distinct geographical locations, better antimicrobial activity was found for UR2 decoction (lower MIC value for K. pneumoniae, M. morganii, E. faecalis and L. monocytogenes), even though this being the sample and extract method with the lowest value of total phenolic compounds (Table 3 ).

The antimicrobial activity of $U$. rupestris leaves methanolic extracts against one Gram-positive and three Gram-negative bacteria has been previously reported by Benhouda et al. (2014). Contrarily to the present work, the authors reported antimicrobial activity against $P$. aeruginosa and $P$. mirabilis, which can be due to different composition of the tested extracts, associated to differences of the extraction method, collection period, edaphoclimatic, and genetic factors, among others (Hansen \& Wold, 2010).

\section{Conclusion}

This work aimed in the characterization of an edible wild plant for which almost no studies have been performed. For the first time, the nutritional composition of $U$. rupestris leaves was thoroughly evaluated, allowing to conclude that this plant can be included in a diet as a source of nutrients and bioactive compounds, such as omega- 3 fatty acids, organic acids, vitamin $\mathrm{E}$ (tocopherols) and phenolic compounds, mainly flavonoids.

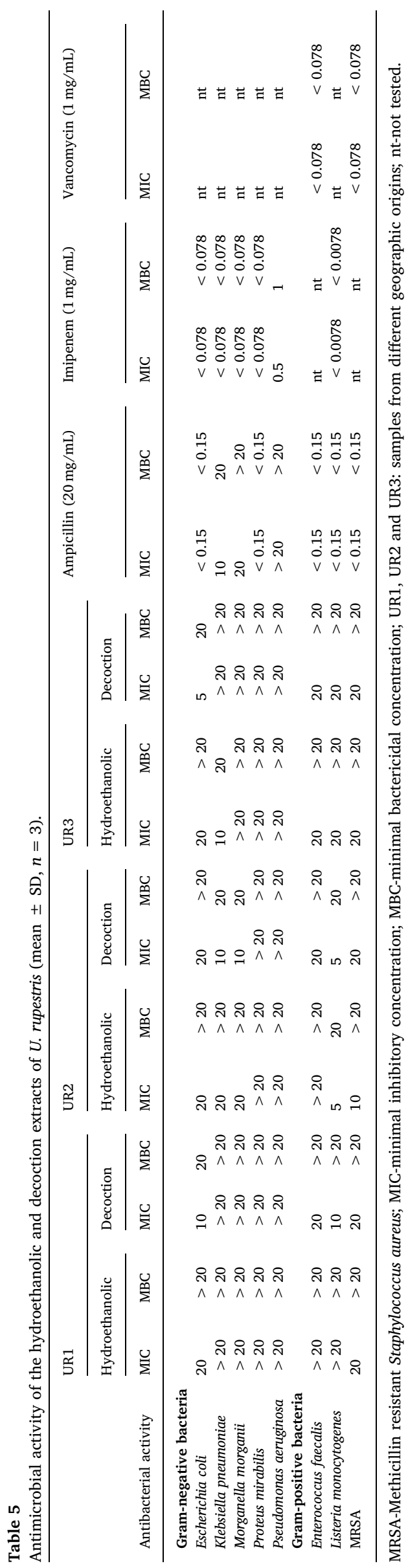


Both the hydroethanolic and decoction extracts were able to promote the scavenging of free radicals, as well as to inhibit lipid peroxidation and prevent oxidative damage. In addition, they did not evidenced cytotoxicity in the assayed concentrations and were capable of inhibiting the growth of different Gram-positive and Gram-negative multi-resistant bacteria. Although several ethnobotanical studies describe the use of this plant for its anti-inflammatory properties, in the present study, both extracts did not evidence such activity in the assayed concentrations. This may be related to the selected assay/tested mechanism in the present study or even to the tested fraction/extract of the plant. In fact, considering that previous in vivo studies have supported the use of $U$. rupestries in traditional medicine for its anti-inflammatory properties, it would be worthwhile to further investigate the hydroethanolic extract using other methodologies (including in vivo assays) as well as testing different fractions containing other compounds such as polysaccharides.

In sum, the results herein reported are a contribution to enhance the preservation and knowledge on neglected and underexploited Mediterranean plant species, that once were seen as valuable food sources but whose consumption currently fell into disuse.

\section{Declaration of Competing Interest}

The authors declare that they do not have any conflict of interest.

\section{Acknowledgements}

The authors are grateful to the Foundation for Science and Technology FCT, Portugal) and FEDER under Programme PT2020 for financial support to CIMO (UID/AGR/00690/2019). L. Barros, R.C. Calhelha, and A. Fernandes thank national funding by FCT, P.I., through the institutional scientific employment program-contract. For their contracts. This work was also funded by FEDER-Interreg EspañaPortugal programme through the project 0377_Iberphenol_6_E.

\section{Appendix A. Supplementary material}

Supplementary data to this article can be found online at https:// doi.org/10.1016/j.foodchem.2019.05.139.

\section{References}

Abreu, R. M. V., Ferreira, I. C. F. R., Calhelha, R. C., Lima, R. T., Vasconcelos, M. H., Adega, F., ... Queiroz, M. J. R. P. (2011). Anti-hepatocellular carcinoma activity using human HepG2 cells and hepatotoxicity of 6-substituted methyl 3-aminothieno[3,2-b] pyridine-2- carboxylate derivatives: In vitro evaluation, cell cycle analysis and QSAR studies. European Journal of Medicinal Chemistry, 46, 5800-5806.

Afferni, M. (2009). Il comune Umbilicus rupestris (Salisb.) Dandy ed il raro Umbilicus horizontalis (Guss.) DC. (Crassulaceae) in Toscana. Società Toscana Di Orticultura, $10-13$.

Allen, D. E., \& Hatfield, G. (2004). Medicinal plants in folk tradition. An ethnobotany of Britain \& Ireland. Timber Press Inc.

Amaral, J. S., Cunha, S. C., Santos, A., Alves, M. R., Seabra, R. M., \& Oliveira, B. P. P. (2006). Influence of cultivar and environmental conditions on the triacylglycerol profile of hazelnut (Corylus avellana L.). Journal of Agricultural and Food Chemistry, $54,449-456$.

AOAC. (2016). Official methods of analysis of AOAC international. The association of official analytical chemists international.

Barros, L., Carvalho, A. M., Morais, J. S., \& Ferreira, I. C. F. R. (2010). Strawberry-tree, blackthorn and rose fruits: Detailed characterisation in nutrients and phytochemicals with antioxidant properties. Food Chemistry, 120, 247-254.

Barros, L., Pereira, E., Calhelha, R. C., Dueñas, M., Carvalho, A. M., Santos-Buelga, C., \& Ferreira, I. C. F. R. (2013). Bioactivity and chemical characterization in hydrophilic and lipophilic compounds of Chenopodium ambrosioides L. Journal of Functional Foods, 5, 1732-1740.

Benhouda, A., \& Yahia, M. (2015). Toxicity and anti-inflammatory effects of methanolic extract of Umbilicus rupestris L. leaves (Crassulaceae). International Journal of Pharma and Bio Sciences, 6, P395-P408.

Benhouda, A., Yahia, M., Benhouda, D., Bousnane, N. E., Benbia, S., Hannachi, N. E., \& Ghecham, A. (2014). Antimicrobial and antioxidant activities of various extracts of hyoscyamus albus L. and umbilicus rupestris L leaves. Retrieved from Algerian Journal of Natural Products, 1, 4-17. https://www.asjp.cerist.dz/en/article/10391.
Bessada, S. M. F., Barreira, J. C. M., Barros, L., Ferreira, I. C. F. R., \& Oliveira, M. B. P. P. (2016). Phenolic profile and antioxidant activity of Coleostephus myconis (L.) Rchb.f.: An underexploited and highly disseminated species. Industrial Crops and Products, 89, 45-51.

Bullitta, S., Piluzza, G., \& Manunta, M. D. I. (2013). Cell-based and chemical assays of the ability to modulate the production of intracellular reactive oxygen species of eleven mediterranean plant species related to ethnobotanic traditions. Genetic Resources and Crop Evolution, 60, 403-412.

Calder, P. C. (2015). Functional roles of fatty acids and their effects on human health. Journal of Parenteral and Enteral Nutrition, 39, 18S-32S.

Carvalho, A. M., \& Morales, R. (2010). Persistence of wild food and wild medicinal plant knowledge in a North-Eastern region of Portugal. In B. Books (Ed.), Ethnobotany in the new Europe: People, health and wild plant resources. (pp. 147-171). Oxford.

Chen, L. S., \& Nose, A. (2004). Day-night changes of energy-rich compounds in crassulacean acid metabolism (CAM) species utilizing hexose and starch. Annals of Botany, 94, 449-455.

Correa, R. C. G., Pereira, Henrique, de Souza, A., Calhelha, R. C., Barros, L., Glamoclija, J., Ferreira, I. C. F. R. (2015). Bioactive formulations prepared from fruiting bodies and submerged culture mycelia of the Brazilian edible mushroom Pleurotus ostreatoroseus singer. Food \& Function, 6, 2155-2164.

Daniel, P. P., Woodward, F. I., Bryant, J. A., \& Etherington, J. R. (1985). Nocturnal accumulation of acid in leaves of wall pennywort (Umbilicus-Rupestris) following exposure to water-stress. Annals of Botany, 55, 217-223.

Divisão de Clima e Alterações Climáticas. (2017). Boletim Climatológico - Portugal Continental. Portugal.

Endo, J., \& Arita, M. (2016). Cardioprotective mechanism of omega-3 polyunsaturated fatty acids. Journal of Cardiology, 67, 22-27.

Ferreira, I. C. F. R., Morales, P., \& Barros, L. (2016). Wild plants, mushrooms and nuts: Functional food properties and applications. Wiley-Blackwell.

Geraci, A., Amato, F., Di Noto, G., Bazan, G., \& Schicchi, R. (2018). The wild taxa utilized as vegetables in Sicily (Italy): A traditional component of the Mediterranean diet. Journal of Ethnobiology and Ethnomedicine, 14, 1-27.

Geydan, T., \& Melgarejo, L. (2005). Metabolismo Ácido De Las Crasuláceas. Scielo, 10, 13.

Gonzáles, A. R., Román, V. L., \& Castro, M. (2009). Plantas Medicinais do Norte de Portugal e Galiza (1st ed.). Portugal: MEL Editores.

Gülçin, I. (2006). Antioxidant activity of caffeic acid (3,4-dihydroxycinnamic acid). Toxicology, 217, 213-220.

Hansen, M., \& Wold, A.-B. (2010). Contents of bioactive compounds in food plants as affected by traditional breeding and environmental factors. In A. Bernhof (Ed.). Bioactive compounds in plants - benefits and risks for man and animals (pp. 212-222). Oslo: The Norwegian Academy of Science and Letters.

Łuczaj, Ł., Pieroni, A., Tardío, J., Pardo-De-Santayana, M., Sõukand, R., Svanberg, I., \& Kalle, R. (2012). Wild food plant use in 21st century Europe: The disappearance of old traditions and the search for new cuisines involving wild edibles. Acta Societatis Botanicorum Poloniae, 82(4).

Machado, D. F. S., Lagôa, A. M. M. A., Ribeiro, R. V., Marchiori, P. E. R., Machado, R. S., \& Machado, E. C. (2013). Baixa temperatura noturna e deficiência hídrica na fotossíntese de cana-de-açúcar. Pesquisa Agropecuaria Brasileira, 48, 487-495.

Obodai, M., Mensah, D. L. N., Fernandes, Â., Kortei, N. K., Dzomeku, M., Teegarden, M., ... Ferreira, I. C. F. R. (2017). Chemical characterization and antioxidant potential of wild ganoderma species from Ghana. Molecules, 22, 196.

Pardo-de-Santayana, M., Morales, R., Tardío, J., \& Molina, M. (2018). Inventario Español de los conocimientos tradicionales relativos a la biodiversidad, Ministerio de Agricultura y Pesca, Alimentación y Medio Ambiente. Madrid.

Pardo-de-Santayana, M., Tardio, J., Blanco, E., Carvalho, A., Lastra, J., San Miguel, E., \& Morales, R. (2007). Traditional knowledge of wild edible plants used in the northwest of the Iberian Peninsula (Spain and Portugal): A comparative study. Journal of Ethnobiology and Ethnomedicine, 3, 27.

Piluzza, G., \& Bullitta, S. (2011). Correlations between phenolic content and antioxidant properties in twenty-four plant species of traditional ethnoveterinary use in the Mediterranean area. Pharmaceutical Biology, 49, 240-247.

Pires, T. C. S. P., Dias, M. I., Barros, L., Calhelha, R. C., Alves, M. J., Oliveira, M. B. P. P., Ferreira, I. C. F. R. (2018). Edible flowers as sources of phenolic compounds with bioactive potential. Food Research International, 105, 580-588.

Sarmento, A., Barros, L., Fernandes, Â., Carvalho, A. M., \& Ferreira, I. C. F. R. (2015) Valorization of traditional foods: Nutritional and bioactive properties of Cicer arietinum L. and Lathyrus sativus L. pulses. Journal of the Science of Food and Agriculture, 95, 179-185.

Sendl, A., Mulinacci, N., Vincieri, F. F., \& Wagner, H. (1993). Anti-inflammatory and immunologically active polysaccharides of Sedum telephium. Phytochemistry, 34, 1357-1362.

Torija-Isasa, M. E., \& Matallana-González, M. C. (2016). A historical perspective of wild plant foods in the Mediterranean area. In Mediterranean wild e. In S.-M. Tardío (Ed.). Mediterranean wild edible plants: Ethnobotany and food composition tables (pp. 3-14). New York: Springer S.

Tucker, J. M., \& Townsend, D. M. (2005). Alpha-tocopherol: Roles in prevention and therapy of human disease. Biomedicine \& Pharmacotherapy, 59, 380-387.

Vickery, R. (2019). Vickery's folk flora: An A-Z of the folklore and uses of British and IRISH plants. Orion Publishing Co.

Viornery, L., Saliba, C., Daskiewicz, J. B., Bayet, C., Comte, G., Fenet, B., \& Barron, D. (2000). Phenylpropanoids from Umbilicus pendulinus. Chemical \& Pharmaceutical Bulletin, 48, 1768-1770.

Woollard, D. C., \& Indyk, H. E. (2003). In encyclopedia of food science and nutrition. London: Academic Press. 